\title{
Relationship between Emotional Intelligence \& Academic Achievement Emphasizing on Creative Thinking
}

\author{
Dr. Mehdi Zirak \\ Department of Education, Torbat-e Heydarieh Branch, Islamic Azad University, Torbat-e Heydarieh, Iran \\ * Elaheh Ahmadian \\ Department of Education, Torbat-e Heydarieh Branch, Islamic Azad University, Torbat-e Heydarieh, Iran \\ *Corresponding Author: Email: Ahmadian.e2013@gmail.com
}

\author{
Doi:10.5901/mjss.2015.v6n5s2p561
}

\begin{abstract}
Studying the relationship between emotional intelligence \& academic achievement emphasizing on students' creative thinking is the purpose of current study. The statistical society included all fifth grade male and female students of Torbat Heidarie state schools from 2012 to 2013. The sample size is 337 out of 2800 existed students based on Cochranformula. Gathering data was done byBradberry\&Greavesemotional intelligence questionnaire and Aabedi questionnaire of creative thinking. The indicator of academic achievement is students' average degree. Data were analyzed using descriptive statistics, Independent Ttest,Pearson correlation coefficient and regression and SPSS 20 software. The results indicate that there is no positive and significant relationship between emotional intelligence \& academic achievement, but there is positive and significant relationship betweencreative thinking \& academic achievement.
\end{abstract}

Keywords: Emotional intelligence, academic achievement, creative thinking.

\section{Introduction}

Transforming society cultural Heritage, developing students' talents and preparing them for active partnershipin society are the main duties of education organization. So training people for preparing them to accept different responsibilities is important. One of the education system challenges in every society is how to get success. Training students in any grade is just for changing their behavior, thinking, attitudes and tasks and finally will be measured as their academic achievement. Students' academic achievement in every society indicates education system success in reaching to people needs, if the education system acts efficiently, students will get to highest academic achievement in different grades. Average degree of students shows their scientific abilities determinant for accepting a job or higher academic level.

On the other hand, we are at the beginning of new century and it seems we cannot measure people achievement and intelligence as before. New intelligence and creativity theories are defined and gradually replaced older ones. We focus not only on students' logical ability but also their creativity, emotions and interpersonal tasks. Goleman (1995) believes intelligence quantity itself cannot show the degree of success. Emotional intelligence, social intelligence and chance have a great role on every person's success. Robinson (2006) states creativity and creative thinking are as important as literacy and must be considered, too. (Hematti, 1387) creative thinking applications is not limited to just science and art, but is useful in every field of people live. Most of people believe creativity transfigures just in art but it's not true completely. Creativity remains as a secret in different fields such as science, literature, music, painting, etc. Psychologies pay more attention to this field. So, creativity can be transfigured in every courses, fields and all educational degrees and even different ages, although its effect on university students and younger children is more important. (Rahnam\& Maleki, 1388) therefore the aim of current study is determining the relationship between emotional intelligence and creative thinking and academic achievement of fifth grade students.

\section{Emotional Intelligence}

Salovey believes emotional intelligence is kind of emotional process which involves correct estimation of us and other people emotions, its organized order and suitable tool that can improve life style. (Haqani et al., 2012) According to 
Goleman people achievement depends on their emotional intelligence that it's changeable and can be learned. (Niaz \&Saud, 2008)

Bradberry et al (2009) determine emotional intelligence as person's ability, talent, recognition task, correct estimation and controlling the senses against other people and groups.Emotional intelligence theories are divided into two groups and models. First group is ability model in which emotional intelligence considers especial kind of intelligence abilities and is part of cognition intelligence. Next group is a mixture model that theorists mix intelligence abilities with some personality characteristics such as being optimistic. Solovey and Mayer are proponents of ability model. Bur-un follows the second model. ( Samari, 2007)

According to Bradberry and Greaves emotional intelligence determinants are:

Self -awareness: recognizing an impression at the occurrence moment is the important part of emotional intelligence.

Self-managing: involves the ability of applying "emotion awareness" for directing positive behaviors and being flexible, it means be able to control emotional reactions in different situations against all people.

Social-awareness: is art of having great connection with people, controlling task and directing other people sense and thoughts. Usually it means understand other people impressions and thoughts.

Managing a relation: it involves the ability of applying "awareness of other's emotions to control and managing their interactions. (Mansouri, 2001)

\section{Creative Thinking}

Facioni (2006) knows creative thinking as a kind of thinking that leads to new approaches, attitudes, perspectives and new ways for understanding things and situations. Henessey \& Amabile (2010) show that creativity is concept of personal differences which tries to explain why some people have higher potentials to provide new solutions. Creativity guides us to change our thinking methods and act as driving power that directs culture. On other statement creative thinking has been introduced as a kind of thinking which its main characteristic is the ability of ignoring unnecessary hypothesis and providing genius thoughts. (Amir hosseini, 1388) As gaining correct habits are occurred in first years of education systems and manifest during different people life periods, Studying creative thinking in primary school becomes important. (Yosefi, Mokhayer, 2003)

\subsection{Creative thinking phases}

To determine probable solutions for having creative thinking is the first step and next step will be emphasize on hypotheses, exams and estimations. Torens defines scientific discovery and make connection as the last phase of creative thinking. (Dhal, 2012)

Creative thinking determinants are:

Being flowing: the ability of producing too many thoughts at certain time

Extension: Considering the details of an idea and thought.

Originality: the ability of making innovative and new thought.

Flexibility: the ability of changing thoughts and variety of ideas.

\subsection{Academic achievement}

Khoynejad determines academic achievement as the amount of a student can reach to educational aims in especial course. Shelvery knows it as person institutional learning that can be measured by different exams such as mathematic and scientific tests. (Hanifi, 2010)Vebster M explains academic achievement as quality and quantity of student's activity. (Sousa \& Amor, 2010) Any achievement in different field of life such as sport, education, industry, occupation is important both for children and people around them. In formal education system, academic achievement is the main criterion for measuring education system in reaching to academic purposes.( Ademola et al ,2010) Studying influential factors on students' academic achievement is complicated matter as it is a multidimensional element and related to intelligence, motivation, personal characteristics, control position, family sentimental situation, family social- economical position, teaching method, class sentimental circumstance and success sense at exam. These factors and variables are such inter-related and have interactions that determining each role and share is problematic. ( La'li, 2009) These factors may decrease academic achievement or increase it through intelligence ability, social and emotional maturity. 


\section{Research Back Ground}

There are so many studies in these field. ( Samari et al, 2007) They found there is positive correlation between university students emotional intelligence and their academic achievement.(Sobhani, 2004)

Habib Allah (2009) did not find any significant relationship between male and female student creativity and academic achievement. Zahabiun \& Ahmadi (2009) found there is no significant relationship between academic achievement and other variables such as the degree of using creative thinking, gender and parents educational level. Hassan zade \& Imani Far (2010) in a study called "relationship between creativity, self-confidence and academic achievement" find there is no significant relationship between academic achievement and creativity.

Pearson correlation analysis shows different dimensions of male and female creativity are related to their academic achievement.(nadeem et al, 2012)another study shows there is no significant difference between all male and female oral creativity except males' innovative criteria.( Sharifi et al, 2012)

Noferesti \& moeen al-qorabai (2010) findings show that there is positive and significant relationship between emotional intelligence and creativity. Most of experts believe that there is a close relationship between male and female emotional intelligence variables and academic achievement in their different age periods. (Farmahini et al, 2008) Niaz \& Saud (2008) show there is positive and significant relationship between academic achievement and creativity. Jim k. has studied 235 first grade students for surveying the correlation between emotional intelligence and academic achievement. The results show there is low correlation between emotional intelligence and academic achievement. (La'li, 2009) After controlling intelligence abilities of Shanghai university students, Singh et al (2009) show emotional intelligence has effect on academic functions. Another American study shows although family situation has considerable effect on students' academic achievement; however it cannot clear the gap between American students' achievement and students from other developed countries. (Soroudi \& Rahimi, 2010)

Extensive studies regarding person's behavior based on emotional intelligence show emotional intelligence has significant effect on academic achievement. (Tamannai et al, 2010) Bharat (2011) through an experiment finds there is a significant difference between rural and urban juniors' emotional intelligence average score. He adds gender has no significant effect on emotional intelligence. Ziugzia (2010) experiments make clear male and female creativity is related to their academic achievement. (Dhal, 2012)

Dhal (2012) based on his experiments show in absence of intelligence effect; there is no significant relationship between secondary school students' creativity and academic achievement. Runco(2007) states creativity has a positive and significant relationship withacademic achievement. Other researchers such as Stroctur et al, (1996), Peterson et al, (2008), Naderi et al, (2010) find academic achievement can be predicted by creativity scores. (Mimrot, 2011) Chaun findings show there is positive and significant relationship between children creativity and emotional intelligence. (Norouzi et al, 1392) Nelson et al, 2004 show emotional intelligence tasks have a significant relationship with creative thinking tasks and can leads to academic achievement. (Jabeen et al, 2013)

\section{Hypotheses}

Hypothesis 1: there is a significant relationship between emotional intelligence and students' academic achievement. Hypothesis 2:there is a significant relationship between creative thinking and students' academic achievement. Hypothesis 3: there is a significant difference between male and female emotional intelligence. Hypothesis 4: there is a significant difference between male and female creative thinking.

\section{Method of Research}

Current study is descriptive and correlative.

\section{Statistical Society}

Statistical society of current study is all male and female fifth grade students of Torbat Heidarie state schools from 1391 to 1392 . According to education organization statistics, among their 2800 students, there are 1430 female and 1370 male students. 


\section{Sample Size and Method of Sampling}

Calculating the sample size is based on Cochran formula, and then suitable samples were chosen among male and female groups.

$$
n=\frac{\frac{z^{2} p q}{d^{2}}}{1+\frac{1}{N}\left(\frac{z^{2} p q}{d^{2}}-1\right)}
$$

Where,

$\mathrm{N}=$ Statistical society size

$\mathrm{n}=$ sample size

$Z=$ normal variable amount of standard unit which at confidence level of $95 \%$ is equal to 1.96 .

$\mathrm{P}=$ the amount of existence a certain adjective in a society. It can be considered equal to 0.05 , if it is undefined. In this way, the sample size and also its variance will be at highest level.

$q=$ the percent of people who do not show that certain adjective $(q=1-p)$

$\mathrm{d}=$ permitted error

In above formula, the utmost permitted error is 0.05 , confidence coefficient $0.95, p \& q 0.5$ and society size is equal to $\mathrm{N}=2800$. According to Cochran formula the sample size is 337 . ( $n=337$ ) 165.

On the other hand, based on sampling method related to size, female sample size is 172 and male sample size is

\section{Gathering Data Method}

Regarding theoretical framework, different resources such as books, magazines, and theses are used. Gathering data have been done by standard questionnaire which distributed among statistical sample.

\section{Research Tool}

\subsection{Emotional intelligence questionnaire}

It has been designed by Bradberry and Greave (2005) and consists of 28 determinants that measures self-awareness, self-managing, social-awareness and managing a relationship. The score of each question is measured based on Likert method. (jabeen et al, 2013) the highest score is 100.the resulted reliability coefficients of two execution scores at first group show self-awareness 0.73 , self-managing 0.87 , social-awareness 0.78 , managing a relationship 0.76 and total score of emotional intelligence equal to 0.90 which becomes significant at level of 0.99

Studying second group data using cronbakhmethod showsall questions have positive and significant correlation with whole exam and removing any question do not increase the validity of whole exam, considerably. (Jahani, 1387)

\subsection{Creative thinking questionnaire}

Creative thinking questionnaire has been designed by Dr Aabedi in 1372 and consists of 60 three optioned questions which measures four factors of creativity (being flowing, innovation, flexibility and extension)(Rahnama \& Maleki Jamal, 1389)

\section{Validity \& Reliability}

As Bradberry \& Greave emotional intelligence test has been translated from English to Persian, the main question appears which characteristics are measured exactly. Therefore, the method of factor analysis and Convergent validityare used. The results show the questions of questionnaire can measure the considered determinants well.

Aabedi studies show there is significant correlation between four factors of both above mentioned exams. For instance, the correlation of two innovative exams is $r=\% 497 \& r=\% 468$ for flowing exams. The resulted coefficient of flowing determinant is 0.75 , innovative determinant 0.67 , flexibility determinant 0.61 and extension determinant is equal to 0.61. Credibility Aabedi test is between $61-75 \%$.As there are too many questions respect to subjects,Cronbach'salphais 
used for studying creative thinking questionnaire. Regarding the results of Cronbach's alpha for research variables, reliability of creative thinking questionnaire is confirmed.

\section{Findings}

Examine first hypothesis, the first hypothesis indicates:

There is significant relationship between emotional intelligence \&students' academic achievement.

Table 1 - The results of correlation coefficient between emotional intelligence \& academic achievement

\begin{tabular}{lcccccc}
\hline & 1 & 2 & 3 & 4 & 5 & 6 \\
\hline 1.self-awareness & 1 & & & & & \\
2.self-managing & $0 / 50^{* *}$ & 1 & & & \\
3.Social awareness & $0 / 34^{* *}$ & $0 / 49^{* *}$ & 1 & & \\
4. managing a relation & $0 / 43^{* *}$ & $0 / 43^{* *}$ & $0 / 43^{* *}$ & 1 & & \\
5. academic achievement & $0 / 07$ & $0 / 07$ & $0 / 26^{* *}$ & $-0 / 004$ & 1 & \\
6. total emotional intelligence & $0 / 73^{* *}$ & $0 / 82^{* *}$ & $0 / 70^{* *}$ & $0 / 77^{* *}$ & $0 / 11$ & 1 \\
\hline
\end{tabular}

The results of correlation coefficient show there is no significant relationship between self- awareness and academic achievement $(r=0.07, p>0.05)$, self-managing and academic achievement $(r=0.07, p>0.05)$, managing a relationship and academic achievement $(r=004, p>0.05)$ and total emotional intelligence and academic achievement $(r=0.11, p>$ 0.05). so the hypothesis is rejected and we can say there is no significant relationship between total emotional intelligence and academic achievement.

Also correlation coefficient results show there is a direct significant relationship between social-awareness and academic achievement. Hence as social-awareness increase, academic achievement will be increased, too and vice versa.

For measuring the relationship between emotional intelligence and academic achievement, stepwise regression has been used. In this method, the predicted variables are analyzed step by step and their effect on criterion variable is studied.

Table 2 - Correlation coefficient of criterion variables of academic achievement \& predicting emotional intelligence

\begin{tabular}{|l|c|c|c|c|}
\hline Step correlation coefficient Square of correlation coefficient & Modified Square of correlation coefficient & Error of estimation criterion \\
\hline first & 0.26 & 0.06 & 0.06 & 1.59 \\
\hline
\end{tabular}

Social-awareness variable has inserted into equation. The amount of multi correlation coefficient is 0.26 and determined coefficient is 0.06 . On the other hand, 0.06 percent of variance of academic achievement can be determined by predicting variables.

Table 3 - The results of regression analyzing of criterion variable of academic achievement \& predicting emotional intelligence

\begin{tabular}{|c|c|c|c|c|c|c|}
\hline Step & Model & Sum of Squares & Degree of freedom & The average of Squares & $F$ & The level of significance \\
\hline \multirow{3}{*}{1} & Regression & $28 / 86$ & 1 & $28 / 86$ & & \multirow{2}{*}{$0 / 001$} \\
\cline { 2 - 7 } & Remaining & $1002 / 24$ & 335 & $2 / 55$ & $11 / 30$ & \\
\cline { 2 - 5 } & Total & $1031 / 10$ & 336 & & & \\
\hline
\end{tabular}

F 1.154 equals to 11.30 at error level of 0.001 is significant. Therefore, social-awareness variable has a significant role on academic achievement variable.

Table 4 - Regression coefficients of criterion variable of academic achievement \& predicting emotional intelligence

\begin{tabular}{|l|l|c|c|c|c|c|}
\hline \multicolumn{2}{|l|}{ Step } & B correlation & Standard Error & Beta & $T$ & The level of significance \\
\hline \multirow{2}{*}{1} & Constant correlation & $16 / 27$ & $0 / 60$ & & $26 / 74$ & $0 / 0001$ \\
\cline { 2 - 7 } & Social awareness & $0 / 09$ & $0 / 02$ & $0 / 26$ & $3 / 36$ & $0 / 001$ \\
\hline \\
0
\end{tabular}


Above table shows that social-awareness variable is a positive prediction of academic achievement. ( Beta $=0.26, p=$ $0.001<0.01)$

Table 5 - Variables removed from equation

\begin{tabular}{|l|c|c|c|c|}
\hline Variable & Beta in & $\mathbf{t}$ & The level of significance & Separated correlation \\
\hline 1.self-awareness & $-0 / 02$ & $-0 / 26$ & $0 / 79$ & $-0 / 02$ \\
\hline 2.self-management & $-0 / 07$ & $-0 / 81$ & $0 / 41$ & $-0 / 06$ \\
\hline 3. management of relation & $-0 / 14$ & $-1 / 66$ & $0 / 09$ & $-0 / 13$ \\
\hline
\end{tabular}

Examinesecond hypothesis, the second hypothesis indicates:

There is significant relationship between creative thinking\&students' academic achievement.

Table 6 - The results ofcorrelation coefficient between creative thinking \&academic achievement

\begin{tabular}{|l|c|c|c|c|c|c|}
\hline & 1 & 2 & 3 & 4 & 5 & $\mathbf{6}$ \\
\hline Academic Achievement & 1 & & & & & \\
\hline flowing & $0 / 34^{* *}$ & 1 & & & & \\
\hline innovation & $0 / 08$ & $0 / 53^{* *}$ & 1 & & & \\
\hline Flexibility & $0 / 09$ & $0 / 49^{* * *}$ & $0 / 54^{* *}$ & 1 & & \\
\hline extension & $0 / 15$ & $0 / 52^{* *}$ & $0 / 66^{* *}$ & $0 / 49^{* *}$ & 1 & \\
\hline Creative thinking & $0 / 21^{* *}$ & $0 / 83^{* *}$ & $0 / 85^{* *}$ & $0 / 74^{* *}$ & $0 / 80^{* *}$ & 1 \\
\hline
\end{tabular}

The results of correlation coefficient show there is no significant relationship between innovative and academic achievement $(r=0.08, p>0.05)$, extension and academic achievement $(r=0.15, p>0.05)$, flexibility and academic achievement $(r=0.09, p>0.05)$

Also correlation coefficient results show there is a direct significant relationship between being flowing and academic achievement $(r=0.34, p<0.05)$ and total score of creative thinking and academic achievement $(r=0.21, p<0.05)$. Hence as creative thinking increase, students' academic achievement will be increased, too and vice versa.

For measuring the relationship between creative thinking and academic achievement, stepwise regression has been used. In this method, the predicted variables are analyzed step by step and their effect on criterion variable is studied.

Table 7 - Correlation coefficient, the criterion variable of academic achievement \& predicting creative thinking

\begin{tabular}{|c|c|c|c|c|}
\hline Step & $\begin{array}{c}\text { Correlation } \\
\text { Coefficient }\end{array}$ & $\begin{array}{c}\text { Square of Correlation } \\
\text { Coefficient }\end{array}$ & $\begin{array}{c}\text { Modified Square of Correlation } \\
\text { Coefficient }\end{array}$ & $\begin{array}{c}\text { Error of Estimation } \\
\text { Criterion }\end{array}$ \\
\hline first & 0.34 & 0.12 & 0.11 & 1.55 \\
\hline
\end{tabular}

Being flowing variable has inserted into equation. The amount of multi correlation coefficient is 0.34 and determined coefficient is 0.11 . On the other hand, 0.11 percent of variance of academic achievement can be determined by predicting variables.

Table 8 - The results of Variable regression analyzing, the criterion of academic achievement \& predictingcreative thinking

\begin{tabular}{c|c|c|c|c|c|c|}
\hline Step Model & Sum of Squares & Degree of Freedom & The Average of Squares & F & The Level of Significance \\
\hline \multirow{3}{*}{1} & Regression & $51 / 43$ & 1 & $51 / 43$ & & \multirow{2}{*}{$0 / 000$} \\
\cline { 2 - 5 } & Remaining & $804 / 67$ & 335 & $21 / 40$ & $21 / 37$ & \\
\cline { 2 - 6 } & Total & $856 / 11$ & 336 & & & \\
\hline
\end{tabular}

F 1.154 equals to 21.37 at error level of 0.01 is significant. Therefore, being flowing variable has a significant role on academic achievement variable. 
Table 9 - Regression coefficient, the criterion Variable of academic achievement \& predictingemotional intelligence

\begin{tabular}{|l|l|c|c|c|c|c|}
\hline \multicolumn{2}{|l|}{ Step } & B correlation & Standard Error & Beta & T & The Level of Significance \\
\hline \multirow{2}{*}{1} & Constant correlation & $13 / 60$ & $1 / 01$ & & $13 / 35$ & $0 / 000$ \\
\cline { 2 - 7 } & Being flowing & $0 / 09$ & $0 / 02$ & $0 / 34$ & $4 / 62$ & $0 / 001$ \\
\hline
\end{tabular}

Above table shows that being flowing variable can predict academic achievement. ( Beta $=0.34, p=0.001<0.01$ )

Table 10 - Variables removed from equation

\begin{tabular}{|c|l|c|c|c|c|}
\hline \multirow{3}{*}{ First step } & Variable & Beta in & $\mathbf{t}$ & The Level of Significance & Separated Correlation \\
\cline { 2 - 6 } & Innovation & $-0 / 14$ & $-1 / 65$ & $0 / 10$ & $-0 / 13$ \\
\cline { 2 - 6 } & Elexibility & $-0 / 11$ & $-1 / 28$ & $0 / 20$ & $-0 / 10$ \\
\cline { 2 - 5 } & Expansion & $-0 / 09$ & $-1 / 07$ & $0 / 28$ & $-0 / 08$ \\
\hline
\end{tabular}

Examine third hypothesis, the third hypothesis indicates:

There is a significant difference between male and female emotional intelligence.

Table 11 - The results of Multivariate AnalysisOfVariance of male \& female students considering emotional intelligence

\begin{tabular}{|l|c|c|c|c|c|}
\hline Exam & Amount & DF Hypothesis & DF Error & $\mathbf{F}$ & The Level of Significance $(\mathbf{p})$ \\
\hline Pillai's trace & $0 / 04$ & $1 / 71$ & $4 / 00$ & $336 / 00$ & $0 / 14$ \\
\hline Wilks's lambda & $0 / 95$ & $1 / 71$ & $4 / 00$ & $336 / 00$ & $0 / 14$ \\
\hline Hotelling's trace & $0 / 04$ & $1 / 71$ & $4 / 00$ & $336 / 00$ & $0 / 14$ \\
\hline Examininf the biggest root & $0 / 04$ & $1 / 71$ & $4 / 00$ & $336 / 00$ & $0 / 14$ \\
\hline
\end{tabular}

As significance level of all exams (table 12) showthere is no significant difference between male and female depended variables such as self-awareness, social-awareness, self-managing and managing a relation. The results of Independent T-test are stated in table 13. Its worth to note, examination of equalvariances is provided firstly.

Table 12 - The resulted of Bartlett test for studying variancesin two groups of male \& female students considering emotional intelligence

\begin{tabular}{|l|c|c|}
\hline Variables & $\mathbf{F}$ & The Level of Significance \\
\hline 1.Self-Awareness & 0.014 & $0 / 88$ \\
\hline 2.Self-Managing & 0.211 & $0 / 42$ \\
\hline 3.Social Managing & 0.541 & $0 / 39$ \\
\hline 4. Management of Relation & 0.012 & $0 / 91$ \\
\hline
\end{tabular}

Table 13 - The results of Independent T-test on male \& female students considering emotional intelligence

\begin{tabular}{|c|c|c|c|c|c|c|c|}
\hline Variable & Group & Number of People & Average & Criterion Error & Amount of $t$ & Degree of Freedom & The Level of Significance \\
\hline \multirow{2}{*}{ Self-awareness } & Male & 165 & $24 / 80$ & $4 / 68$ & \multirow{2}{*}{$0 / 718$} & \multirow[b]{2}{*}{335} & \multirow{2}{*}{ 0/773 } \\
\hline & female & 172 & $23 / 22$ & $5 / 92$ & & & \\
\hline \multirow{2}{*}{ Self-managing } & Male & 165 & $37 / 78$ & $6 / 23$ & \multirow{2}{*}{$0 / 625$} & \multirow{2}{*}{335} & \multirow{2}{*}{$0 / 812$} \\
\hline & female & 172 & $36 / 86$ & $8 / 13$ & & & \\
\hline \multirow{2}{*}{ Social Managing } & Male & 165 & $20 / 93$ & $3 / 54$ & \multirow{2}{*}{$-0 / 618$} & \multirow{2}{*}{335} & \multirow{2}{*}{$0 / 510$} \\
\hline & female & 172 & $21 / 32$ & $5 / 44$ & & & \\
\hline \multirow{2}{*}{ Management of Relation } & Male & 165 & $34 / 38$ & $5 / 75$ & \multirow{2}{*}{ 0/918 } & \multirow{2}{*}{335} & \multirow{2}{*}{$0 / 381$} \\
\hline & female & 172 & $32 / 73$ & $7 / 14$ & & & \\
\hline
\end{tabular}

According to table 12, equal variances hypothesis has been accepted for both groups and table 13 there is no significant difference between male and female self-awareness, self-awareness, social managing and management of relation.

Examine forthhypothesis, the forth hypothesis indicates:

There is a significant difference between male and female creative thinking. 
Table 14 - The results of Multivariate Analysis of Variance of male \& female students considering creative thinking

\begin{tabular}{|l|c|c|c|c|c|}
\hline Exam & Amount & DF Hypothesis & DF Error & $\mathbf{F}$ & The Level of Significance (p) \\
\hline Pillai's trace & $0 / 04$ & $1 / 71$ & $4 / 00$ & $336 / 00$ & $0 / 14$ \\
\hline Wilks's lambda & $0 / 95$ & $1 / 71$ & $4 / 00$ & $336 / 00$ & $0 / 14$ \\
\hline Hotelling's trace & $0 / 04$ & $1 / 71$ & $4 / 00$ & $336 / 00$ & $0 / 14$ \\
\hline Exam biggest root & $0 / 04$ & $1 / 71$ & $4 / 00$ & $336 / 00$ & $0 / 14$ \\
\hline
\end{tabular}

As significance level of all exams (table 12) show there is no significant difference between male and female depended variables such as being flowing, innovation, flexibility and extension. The results of Independent T-test are stated in table 15.

Table15 - The resulted of Bartlettest for studying equal variancesin two groups of male \& female students considering creative thinking

\begin{tabular}{|l|c|c|}
\hline Variables & $\mathbf{F}$ & The Level of Significance \\
\hline Being Flowing & 0.321 & $0 / 52$ \\
\hline Innovation & 0.483 & $0 / 48$ \\
\hline Flexibility & 0.531 & $0 / 41$ \\
\hline Extension & 1.225 & $0 / 21$ \\
\hline
\end{tabular}

Table 16 - The results of Independent T-test on male \& female students considering creative thinking

\begin{tabular}{|c|c|c|c|c|c|c|c|}
\hline Variable & Group & Number of People & Average & Criterion Error & Amount of $t$ & Degree of Freedom & The Level of Significance \\
\hline \multirow{2}{*}{ Being Flowing } & Male & 165 & $47 / 82$ & $6 / 38$ & \multirow{2}{*}{$-0 / 718$} & \multirow{2}{*}{335} & \multirow{2}{*}{$0 / 773$} \\
\hline & female & 172 & $49 / 42$ & $5 / 12$ & & & \\
\hline \multirow{2}{*}{ Innovation } & Male & 165 & $34 / 71$ & $6 / 23$ & \multirow{2}{*}{$1 / 625$} & \multirow{2}{*}{335} & \multirow{2}{*}{$0 / 221$} \\
\hline & female & 172 & $33 / 45$ & $5 / 13$ & & & \\
\hline \multirow{2}{*}{ Flexibility } & Male & 165 & $24 / 13$ & $3 / 54$ & \multirow{2}{*}{$0 / 618$} & \multirow{2}{*}{335} & \multirow{2}{*}{$0 / 510$} \\
\hline & female & 172 & $23 / 38$ & $5 / 44$ & & & \\
\hline \multirow{2}{*}{ Extension } & Male & 165 & $22 / 21$ & $3 / 25$ & \multirow{2}{*}{ 0/008 } & \multirow{2}{*}{335} & \multirow{2}{*}{$0 / 981$} \\
\hline & female & 172 & $22 / 75$ & $3 / 32$ & & & \\
\hline
\end{tabular}

According to table 15, equal variances hypothesis has been accepted for both groups and table 16 shows there is no significant difference between male and female self-awareness, self-awareness, social managing and management of relation.

Finally, following results are provided for male and female comparison of emotional intelligence, creative thinking and academic achievement.

Table 17 - The resulted of Bartlett test for studying equal variancesin two groups of male \& female students considering total emotional intelligence, creative thinking and academic achievement

\begin{tabular}{|l|c|c|}
\hline Variables & (مار) F & The Level of Significance \\
\hline Emotional Intelligence & 0.342 & $0 / 52$ \\
\hline Creative Thinking & 0.381 & $0 / 51$ \\
\hline Academic Achievement & 0.651 & $0 / 42$ \\
\hline
\end{tabular}

Table 18 - The results of Independent T-test on male \& female students considering total emotional intelligence, creative thinking and academic achievement

\begin{tabular}{|c|c|c|c|c|c|c|c|}
\hline Variable & Group & Number of People & Average & Criterion Error & Amount of $t$ & Degree of Freedom & The Level of Significance \\
\hline \multirow{2}{*}{ Emotional Intelligence } & Male & 165 & $114 / 21$ & $20 / 44$ & \multirow{2}{*}{$-0 / 521$} & \multirow{2}{*}{335} & \multirow{2}{*}{$0 / 813$} \\
\hline & female & 172 & $117 / 35$ & $16 / 56$ & & & \\
\hline \multirow{2}{*}{ Creative Thinking } & Male & 165 & $129 / 85$ & $14 / 14$ & \multirow{2}{*}{$-0 / 125$} & \multirow{2}{*}{335} & \multirow{2}{*}{$0 / 931$} \\
\hline & female & 172 & $130 / 55$ & $15 / 45$ & & & \\
\hline Academic Achievement & Male & 165 & $18 / 64$ & $1 / 50$ & $1 / 218$ & 335 & $0 / 112$ \\
\hline
\end{tabular}


Above table shows male and female students' average and criterion error of research variables. Independent T-test indicates academic achievement is different between male and female students, although it's not a significant difference.

\section{Results \& Discussions}

There are different results regarding lack of coordination between emotional intelligence and academic achievement. It may be due to inattention to previous theoretical foundations and tests. Probably one of the reasons may refer to incorrect understanding of students about emotions. We can consider Bradberry \& Greaves statement that only $26 \%$ of people can correctly explain their emotions. Sharifi et al, 2011 find there is no significant relationship between creativity and emotional intelligence and academic achievement. we can conclude that primary schools focus on oral relationship and pay less attention to higher level of education such as mix level, critical thinking, solving a problem and emotional intelligence. Perhaps one of the reasons of this difference is due to low efficiency of creativity measuring exams. Because they consider creativity as general adjective however it is related to especial cognition area. They refer to creativity as a general phenomenon, so their application value is low. ( Bani Hashemian et al, 2012) Pour Saeed's research (1999) shows significant relationship between total creativity and four dimensions of being flowing, credibility, flexibility and extension $0.76,0.75,0.68$ and 0.56 respectively. According to above mentioned calculations and their importance we can order them as being flowing and innovation, flexibility and extension. So being flowing and innovation have more important role in creativity. Current study has similar results. So we prefer being flowing and innovation determinants. Previous students' experiences and knowledge are important for developing their creative thinking. If students benefit rich knowledge and facilities, the possibility of creative thinking will increase. It seems although there are lots of facilities, however students benefit low information, perhaps be due to rough and fast computer games. Unfortunately, teachers instead of providing new matters and using various facilities, choose easier teaching methods such as providing lecture teaching method instead of cooperative methods. In this study we have considered governmental schools. Low literacy level of parents and their incorrect behavior is another reason of low scores of creative thinking. Jahani (1998) believe parents who desire creative children, should not criticize the children, contempt their fantasy and avoid unnecessary punishment. Another reason is low scores of emotional intelligence. Bani hashemian (2012) explains most of people believe creativity is domain of emotional intelligence and is one of its determinants. Emotional intelligence can lead to increasing of positive creation. So indirectly increase creative thinking. Regarding studies back ground and creative thinking field we can conclude creativity is teachable and children can learn it through creative tasks. However there is no unique agreement among experts which concepts and methods are suitable. Gilford suggests teaching thinking, Dobuno refers to developing thinking style by learning courses and Limpen believes we can develop creative thinking through teaching philosophic concepts. ( Jabeen,et al, 2013)

Suggestions: education organization emphasize on developing social tasks, emotional intelligence and itsdifferent dimensions of primary schools can lead to developing emotional intelligence and creative thinking. Emotional learning that leads to emotional intelligence must be considered as a $\mathrm{n}$ important matters of training teachers. Some developing emotional intelligence classes must be provided for parents to know how react with their children at home and what matters are taught to them at school.

\section{References}

Ademola Olatoye, Akintunde,S.O., \& Yakasi,M.I. (2010). Emotional intelligence, creativity and academic achievement of business administration students. Electronic Journal of Research in Educational Psychology,8(2)763-786

Bradberry,Travis \& Greaves, Jean. (2009). Emotional Intelligence. San Francidco: publisher group west

Dhall. S. (2012). A Study of creativity in relation to reactions of frustration and academic achievement of secondary school . Indian . J. Innovations, Vol.1,No.6

Jabeen, S. \& Ahmed Khan,M. (2013). A study of creative thinking abilities and self concept of high and low achievers. Unique Journal of Educational Research.Vol.1(1),pp 001-011

Mimrot, Bharat, H. (2011). Role of area of residence, sex in developing emotional intelligence and self of adolescents. International Referred Research Journals. June Vol. 2,issue 21

Nadeem. M., Aness. M., Khizar.A., Naseer. M, Muhammad.G. (2012). Relationship of creative thinking with the academic achievement of secondary school students. International Interdisciplinary Journal of Education,Vol.1,Issue 3

Niaz, Mansoor., \& Saud, Grecia. (2008). Academic performance of high school students and a function of mental capacity, cognitive style, mobility - fixity dimension, and creativity. Journal of Creative Behavior. VOL. 34, Number1 
Norouzi Kouhdasht, R.; Mahdian, M. J; Afzali Naeini, M. (2013).The relationship between emotional intelligence and three thinking style in male and female students in Tehran. International Journal of Learning Development. Vol.3.No3.110-119

Sousa, S \& Amor, D. J. (2010). Impact of family vs school factors on cross-national disparties in academic achievement . Social Science Research Network(SSRN).

Ahmadi, M (2007) normalization of Torence creative thinking for high school students in Tehran, MA thesis, Imam Khomieni university

Amir Hosseini, Khosro (2009) creativity and innovation, Aref publications.

Soroudi, Rafie \& rahimi, Naeeme (2010) comparison of emotional intelligence of rural \& urban girls in Qeshm prolimary schools.

Rahna, akbar \& abd almaleki, Jamal (2009)studying the relationship between emotional intelligence \& creativity

Bradberry \& greaves(2005) emotional intelligence(tasks \& exams), Mahdi Gaanji, translator

Bani hashemian, Koroush, Fakhri, mohammad Kazem\& mirzain, Bahram (2012) the correlation between general healthy and emotional intelligence, Sari university students

Tamanai far, Mohamad Rezam Sediqi Arfai, Fariborz \& salami mahmood abadi, Fateme (2010) the relationship between emotional intelligence and self confidence with academic achievement

Pour saeed, seyed Masoud (2001) studying relationship between creativity and progress

Samari, Ali Akbar \& Tahmasebi, Fahime (2007) studying relationship between university students emotional intelligence \& academic achievement

Jahani, Jafar (2008) Teaching creative thinking to juniors: reseachal based.

Hassan zade, Ramadan \& Imani far, Parisa (2010) the relationship between creativity and self confidence of young \& junior academic achievement.

Hanifi , Fariba \& juybari, Azita (2010) stydying the relationship between emotional intelligence and student academic achievement Tehran

Sharifim Nastaran, Ganji, Hashemian(2011) comparison of cognition intelligence, creativity and emotional intelligencein predicting students academic achievement

Sharifim Nastaran, Ganji, Hashemian(2011) life school an organization for cognition abilitiesm their creativity and emotional intelligence.

Farmahini farahani, Mohsen, Abdalmaleki, jamal \&Rashidi, Zahra (2008) studying the relationship between emotional intelligence and self learning with academic achievement for Qarve High school students.

La'li, faz, Ahmad \& Askari, Abbas (2008) the ability of predicting emotional intelligenceand population variablesin academic achievement

Sobhani, r, (2004) Studying the relationship between emotional intelligence and academic achievement problems, MA thesis, azad university

Hemati,A (2008) comparative studying of personal obstles for creativity from male and female Oromie teachers poin of views

Yousefi, Faride, Mokhayer , Muhammad (2003) studying the emotional awareness and reasoning with academic achievement of Shiraz high talent and ordinary students. 